\title{
Services of Harvard Library and the Enlightenments for Other Academic Libraries
}

\author{
Xiaofen Zhao, Li Lin, Yan Zhang* \\ Qingdao University of Science and Technology Library, Qingdao, China \\ Email: *zy@qust.edu.cn
}

How to cite this paper: Zhao, X., Lin. L. and Zhang, Y. (2019) Services of Harvard Library and the Enlightenments for Other Academic Libraries. Voice of the Publisher, 5, 49-61.

https://doi.org/10.4236/vp.2019.53004

Received: September 20, 2019

Accepted: September 27, 2019

Published: September 30, 2019

Copyright $\odot 2019$ by author(s) and Scientific Research Publishing Inc. This work is licensed under the Creative Commons Attribution International License (CC BY 4.0).

http://creativecommons.org/licenses/by/4.0/

\begin{abstract}
As the largest university library in the world, Harvard Library is an important indicator of Harvard University as a world-class university. Harvard Library possesses extremely rich resources, advanced facilities and distinctive features, supplying first-class services. Harvard Library not only serves teaching, learning and scientific research, but also provides distinctive and refined services, humanized services for disadvantaged groups, public services for the society, as well as many international exchanges with academic libraries in other countries. The service systems of Harvard Library provide constructive references for other academic universities especially those in China. Academic libraries could actively learn from Harvard Library and substantially improve their construction and service levels, providing high-quality services for their students, teachers, researchers, and even the public.
\end{abstract}

\section{Keywords}

Harvard University, Academic Library, Enlightenment, Library Service

\section{Introduction}

Many countries including China are carrying out the construction of world-class universities and first-class disciplines. University libraries, as one of the important symbols of universities, are an indispensable part of the construction. A university cannot become a first-class university without a first-class library. As an important part of world-class universities, the construction, management, service and management of Harvard libraries has attracted great interests [1]-[6]. This article mainly introduces the services and characteristics of Harvard Library in teaching, learning and research, to provide some references for the construction and development of other academic libraries. 


\section{An Overview on Harvard Library}

Harvard Library was founded in 1638. At the beginning of its establishment, the library had only 400 books left by John Harvard. Harvard Library is considered as the oldest library in the United States, the largest university library and the largest academic library network in the world. Harvard Library ranks the third largest collection in the United States, after the Library of Congress and the Boston Public Library. Its collections include nearly 20 million volumes, 400 million manuscripts, 10 million photographs, and one million maps. Its largest main library is the Widener Library, which is the landmark building of Harvard Yard. Harvard Library is open to current Harvard affiliates, providing services for 6700 undergraduates, 14,500 postgraduates, 2400 faculty members and 10,400 scientific researchers including affiliated hospitals. Additionally, some resources and spaces are open to the public. According to the statistics in 2013, 733,890 books were circulated, 131,041 consultations answered, 20,000 researchers supported, 1700 introductory services held, 42,000 pictures viewed, 17,000 files downloaded, 47,000 documents scanned and transmitted, and 48,700 copies were interlibrary-borrowed. The cumulative opening time reached 55,176 hours for a total of readers of about 19,000 .

\section{Resources and Facilities}

The Harvard Library System currently consists of 79 separate library units, most of which are located in Cambridge, Massachusetts, two in Washington, one in Chicago, and one in Florence, Italy. It has a total collection of 20.4 million volumes, 180,000 serial titles, 13 million monographs, an estimation of 400 million manuscript items, 10 million photographs, 1 million e-books, 500 research databases, precious archives and manuscripts over 200,000 feet long, another 124 million archived web pages and 5.4 TB of born-digital archives and manuscripts. Its electronic resources are very rich, covering natural and social sciences and other disciplines (Figure 1). It has collections of 458 languages from all over the world, covering all disciplines. The Middle East Branch has collections of more than 40 languages. The characteristic resources of each branch library are increasing year by year.

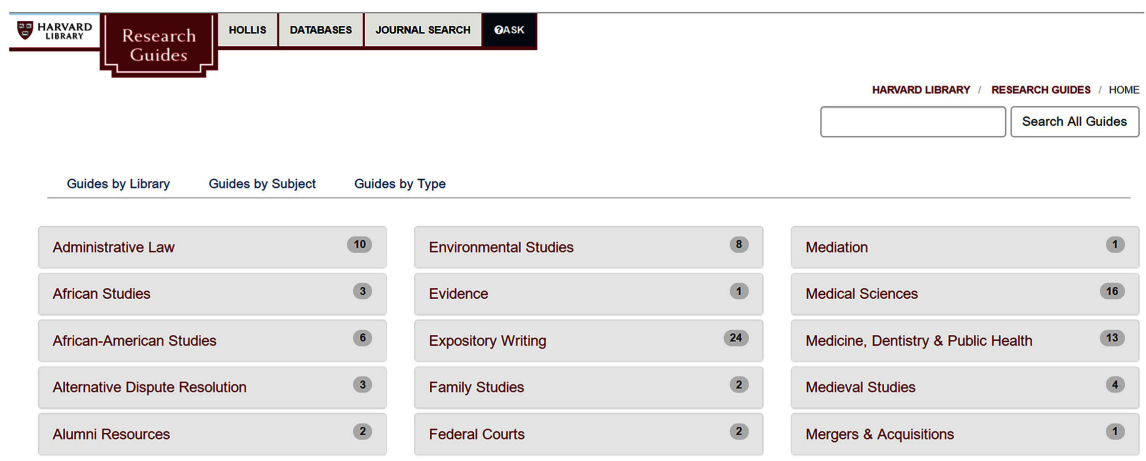

Figure 1. Research guides of Harvard Library. 
Each branch of Harvard Library has its irreplaceable characteristic resources. Different branches have various types of characteristic collections, which are oriented to teachers and students of different majors and focus on different fields. Harvard University has signed a long-term agreement with Google, which aims to continuously digitize many thematic materials such as rubbings, famous manuscripts, photographs and other collections, in order to construct some characteristic databases. The branch libraries of each school set up characteristic databases according to their own subject characteristics.

The resources of each branch are usually unique. Taking Harvard-Yenching Library as an example, it mainly serves the research of East Asia. Its literature resources mainly focus on the politics, economy, culture and history of East Asia. It has abundant rare books, local chronicles and books in minority languages. The library has a collection of about 1.4 million copies, including more than 810,000 Chinese books and 150,000 Chinese ancient books, such as block-printed copies, transcripts, original local chronicles, rubbings, and calligraphy [7]. Yenching Library also has a large number of local chronicles (mainly county chronicles) of China, totaling 3858 kinds, of which 3525 were original local chronicles. In addition, it has more than 340,000 books in Japanese, 170,000 in Korean, 20,000 in Vietnamese, 50,000 in various Western languages, 4300 in Tibetan, 3500 in Manchu and 500 in Mongolian. Its collection in East Asia research is second only to that in the Library of Congress of the United States, and rare books ranks first in Europe and the United States.

Harvard's main branch libraries, such as Weidner Library, Law School Library and Yenching Library, have complete and advanced facilities. They are usually equipped with computers, scanners, photocopiers, and so on. Readers can use computers to search catalogs, data retrieval and information browsing. Readers with Harvard ID can download electronic materials from library network resources and can also use their own mobile devices for wireless Internet access. There are refrigerators, microwave ovens and water fountains in the Weidner Library for readers. Some braches also have restaurants and cafes to provide catering services.

\section{Services of Harvard Library}

\subsection{Teaching, Learning and Research Services}

The mission of Harvard Library is: "to advances scholarship and teaching by committing itself to the creation, application, preservation and dissemination of knowledge". Harvard Library is excellent in integrating teaching, learning, and research. Especially, some school libraries provide all-round teaching and research services with professional characteristics for teachers and students. Readers can communicate with staff face to face, online, or by telephone or email. Harvard Library provides "Research Guides" (Figure 1) or "Course Guides" (Figure 2), which provide reference materials for scientific research and teaching. Research and course navigation are classified according to subject or type, it is easy to find a variety of related resources. 


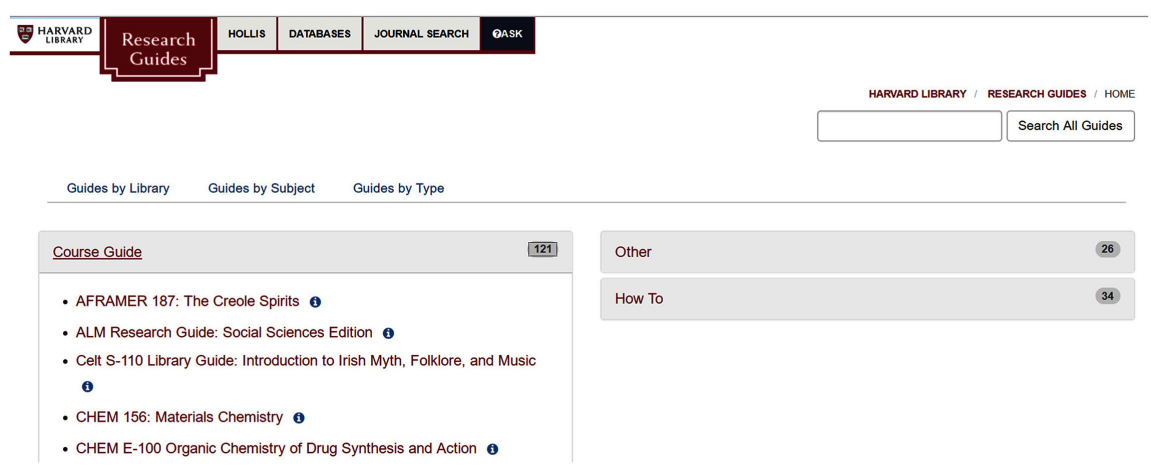

Figure 2. Course guides of Harvard Library.

Harvard Medical School Library offers dozens of courses, tutorials and seminars (Figure 3), including literature retrieval, database, software usage, data analysis, such as Endnote and PubMed, as well as biomedical specialty courses, and personal information management guidance. People with interests can choose courses directly (some require Harvard ID). In terms of research services, reference librarians can provide information consultation and management services for individuals and groups. The library can help users to contact the students, teachers and staff of Harvard Medical School, Harvard Public Health School, and dental science, as well as researchers from the Boston Medical Library. These reference librarians can provide information and consultation in writing fund applications and academic papers, including topic selection, information retrieval and analysis, literature search and so on, almost throughout the entire research activities.

Harvard Business School Library's primary goal is to serve teaching, learning and research. The staff of the library are divided into different teams providing curriculum service, research service, information management service and others. Course service refers to the characteristic service provided around the course teaching and learning. Teachers can always submit a list of information required for a course to their staff. Before the opening of the course, the staff will mark the electronic records of some bibliographies in the library into teaching reference bibliographies and put them on the corresponding shelves for teachers and students to borrow. Teachers can upload the electronic documents and courseware to the teaching platform, and students who take this course enter the platform by password for downloading and learning. The interface that librarians and readers see in the system is totally different. These measures can effectively protect the intellectual property rights of teachers.

Other services for teaching include teaching preparation services, technical assistance, course website construction, provision of reference materials and full-text links, course-related data collection, project plans, student assignments, classroom learning activities, course platform and reference design, skills and methods of research reports, and so on [1]. The librarians and teachers work closely together to integrate information resources, technology and personal intelligence into the whole process of teaching and provide a series of technical 


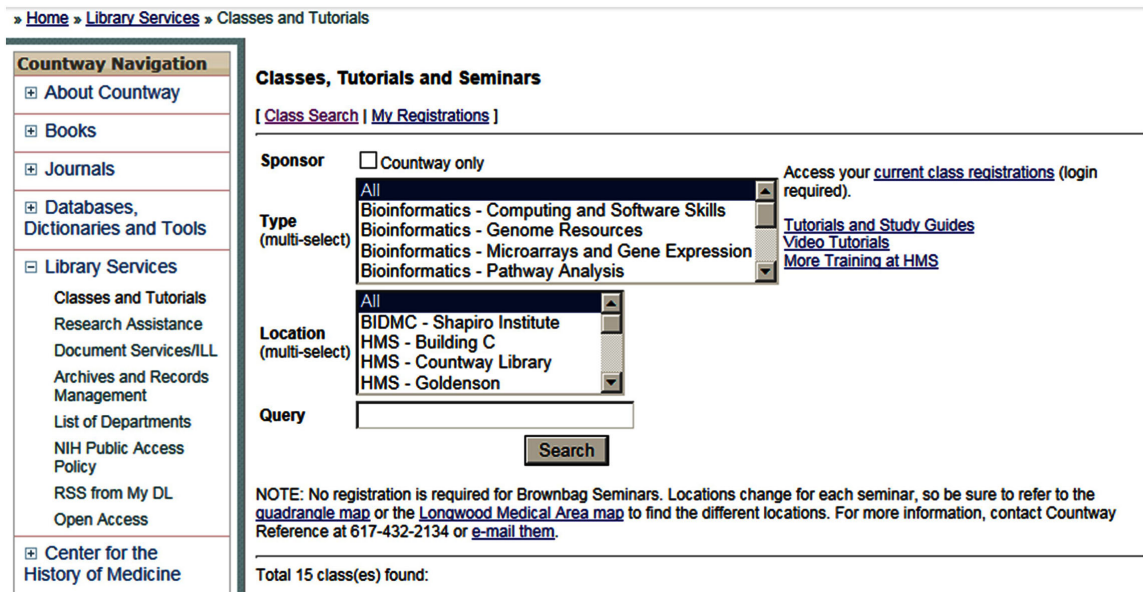

Figure 3. The courses, tutorials and seminars provided by Harvard Medical College Library.

support and knowledge services in course design and planning, subject development and teaching resources.

Research services are also very rich. In the project of HBS Working Knowledge (http://hbswk.hbs.edu), the library and Harvard Business School have jointly set up an exchange platform. Teachers publish their research ideas, plans, various materials and discussions on this platform, which are conducive to promoting academic exchanges. In addition, Harvard libraries provide various research tools online, such as Citation Linker, RefWorks, and Harvard LibX.

\subsection{Refined Services}

The refinement of Harvard Library's service exists everywhere. In the library of Harvard Business School, according to the different needs of readers, it can provide simple self-service and deep-seated one-to-one consulting services, such as solving difficult problems, providing information, prediction of discipline dynamics, tracking service of academic activities, literatures, academic evaluation and so on. It can also help to solve the specific requirements of readers, providing decision-making of scientific research programs, and knowledge innovation and value-added services.

For different levels of users, librarians with different responsibilities also provide different levels of services. Some librarians are subject experts with extensive professional backgrounds and research experiences. They are very familiar with the research advances of the subject and are responsible for the development of the resources of the subject. They can help readers find and use library resources, or design research programs for courses, dissertations and other scientific research projects, not only for students, but also for teachers and other researchers. When users select subject experts from different fields to consult in the library reference platform, they will enter the consulting platform of professional libraries, and get high-quality services from these subject experts.

In the library of Law School, all students from Law School can apply to the li- 
brarians by e-mail to arrange a consultation discussion on their research topics, and seek help for their topic selection, data acquisition, and understanding of the frontiers and latest developments of the research topics. The research librarians are also interested in students' research topics. After making a comprehensive evaluation, both sides can conduct a special research consultation once the discussion time is determined.

\subsection{Characteristic Services}

The collections of Harvard Library have different characteristics, with different service objects and contents. Taking Yenching Library as an example, the library is aimed to collect and sort out academic and research literatures about East Asia. After years of development, the library has become one of the largest regional research and documentation centers in East Asia research in the United States, providing strong support for East Asia research and related teaching services. Harvard Herbarium Library has more than 5 million specimens of algae, mosses, fungi and vascular plants, precious books, manuscripts, on-site records and historical letters, as well as monographs, periodicals and electronic resources, which together form the largest collection of specimens in the world. It has become one of the core institutions of biodiversity science since the beginning of the 19th century, providing a large number of valuable materials for biology teaching and scientific research. The library supports the learning and research of teachers, researchers, staff and students, as well as visiting scholars.

Another characteristic service of Harvard Library is open to the public. For example, the Schlesinger Library at Radcliffe Campus of Harvard University is open to readers all over the world. If you have an ID card or a driver's license and other valid certificates, you can fill out an information sheet to use the resources free of charge, with equal rights to the readers who hold the ID of Harvard University. The Houghton Library does not require any certificates and is open to all readers, but some stack rooms are open only at 2 p.m. on Fridays, providing specialized interpretation services. Since Lamont Library has a special collection of government documents and materials, it provides special services only for readers who use relevant government information resources.

\subsection{Services for Special Groups}

Harvard Library is committed to providing equal services to all readers, so it strives to provide the disabled readers with possible services, including on-site borrowing, retrieval, online search, copying, reference and any other booking services. All libraries have accessible facilities for disabled readers. Every library website has a detailed introduction of facilities and equipment for disabled readers, such as entrances and exits, elevators, toilets, as well as workstations, photocopying, printing, scanning equipment and multimedia resources for wheelchair users. Staff members will provide some services beyond the common scope. In the reading room, notebook users are usually required to turn off the audio 
function, but hearing-impaired readers can contact the staff in advance if they need. Some reading rooms are equipped with magnifiers and desk lamps for users with visual impairment. For some libraries with inaccessible facilities, disabled readers can call in advance and then get help. These services ensure that disabled students enjoy the same educational and reading rights as common students at Harvard.

\subsection{Borrowing Services}

Normally, readers who read or borrow books from Harvard Library must have a Harvard ID or library card. Access to campus electronic resources requires Harvard IP or ID. Because of copyright and other reasons, it is difficult for off-campus users to access electronic resources. All the collections of Harvard Library are open to readers, who can go deep into the library for browsing and consulting. Generally, there is a map of bookshelf distribution in the front desk or on the wall. New readers can have a general understanding of the location of books. Of course, more readers check bibliographies and places online first. Readers may borrow books for up to one semester (28 days for some items), but once other readers need to use them, borrowers will receive letters or e-mails informing them of an appointment. This book must be returned within 10 days to ensure that all readers have equal access to information. Undergraduates and junior graduates borrow books for much shorter periods. Up to five renewals (the fifth must be handled in the library) can be made at the library or online. Books that are temporarily unavailable can be reserved online. There are different regulations on the period of borrowing periodicals and multimedia materials in different branches. Some items belong to non-circulating items and can only be used in the library but cannot be lent out. Some branch libraries have special rules for some special readers, such as audios and videos are non-circulation items in Loeb Music Library, but teachers and teaching assistants in music department can borrow them for two weeks to prepare lessons.

The library has reservation service. Readers can list the books they need, and the library can deliver books to the door. Because of the increasing collection but the limited space of the library, the rare books and documents are mostly located in the Harvard Depository far from the campus. Readers can inquire and make reservations. Every day, the library will collect the required books for readers. Readers can go to the library to collect them before $3 \mathrm{p} . \mathrm{m}$. on the next working day. If teachers need to read some special books, the library will collect and deliver the books after they received the list. Some documents, such as those urgently needed by many people, are scanned into computers by staff members and transmitted to multiple readers.

Harvard Library and Massachusetts Institute of Technology (MIT) Library have signed a reciprocal agreement. Some teachers and students of the Faculty of Arts and Sciences can borrow from each other's library. Additionally, Harvard is part of the Research Collections and Preservation Consortium (ReCAP), and the 
Ivy Plus Libraries Confederation, making over 90 million books available to the Library's readers. The members include Princeton University, MIT, Cornell University, University of Pennsylvania, Yale University, University of Chicago, and Columbia University, Brown University, Dartmouth College, and the Center for Research Libraries in Chicago (279 members, mainly colleges and institutes).

\subsection{Search and Retrieval Services}

Because Harvard Library has abundant collections and many branches, in order to save time and improve efficiency, the library has constantly improved its retrieval system, integrating traditional collection resources with digital resources. Besides the largest HOLLIS (Harvard Online Library Information System) resource retrieval system, it also organized different collection resources based on different research subject groups (research a topic). It developed various types of information retrieval systems according to the particularity of collections of professional libraries, such as HGL (Harvard Geospatial Library) searching geospatial data information, OASIS (Online Archival Search Information System) searching archives, manuscripts, photographs, paintings, etc., Material Library as a research and display platform for various building materials, especially new materials, VIA (Visual Information Access) of visual resources, and IQSS Dataverse Network database of social science research data, etc. All items, such as books, electronic resources, journals, magazines, newspapers, audio/video, pictures, archives, dissertations, manuscripts, government documents, maps, microfilms, music scores, and data files, can be found on the library homepage website, providing great convenience for readers to use resources.

Taking HOLLIS as an example (Figure 4), when retrieving books, the items including keywords, topics, titles and authors can be searched. The search results will clearly show the detailed information of the book (title, author, publishing house, age, page number, book serial number, subject, content introduction, etc.), whether it is available to borrow, where it is collected, and with links to the location of the collection and maps. The citation links Endnote, Refworks and so on are attached to facilitate the citation of this book. Readers who find the book in the system but not in the library can inform the staff. "Borrow direct" search requires readers' ID to login. Interestingly, it can be retrieved by not only English, but also other language such as Chinese. The search results include Harvard libraries and other libraries offering inter-library borrowing.

\subsection{Consultation Services}

Library consultants are proficient in professional literature knowledge, familiar with collection structure, database characteristics and information development trends, and can provide consultation to readers. They can answer readers' questions and provide personalized services according to the actual situation of readers, such as introduction on the collection or database of the library, how to use data, in-depth consultation on a specific topic or subject field, etc. Research 
librarians provide one-to-one consulting services for students to help them select topics, draw up research plans, design and use database resources, and tap potential research problems. In addition to on-site consultation, Harvard Library website provides contact information for each employee, which can be consulted by e-mail, telephone and other means. The library website provides online consultation services. Readers can leave messages and ask questions online and get answers from professionals. For example, on the Harvard Library Reference Platform (Ask a Librarian) (Figure 5), users can ask questions and browse FAQ. Generally, they can get reply within 24 business hours.

\subsection{Document Storage and Preservation}

Due to the increasing collections, Harvard University has established Harvard Depository (http://hul.harvard.edu/hd/) in Southborough, 28 miles west of Cambridge. It adopts highly intensive storage equipment to store paper documents and microfilms, and archives from different Harvard departments, with strict environmental control measures [8]. Harvard Depository is managed by the Harvard Library and is used by the branch libraries of the whole university. When readers borrow from Harvard Depository, they can fill in an online application form to obtain the documents and determine the branch to be served.

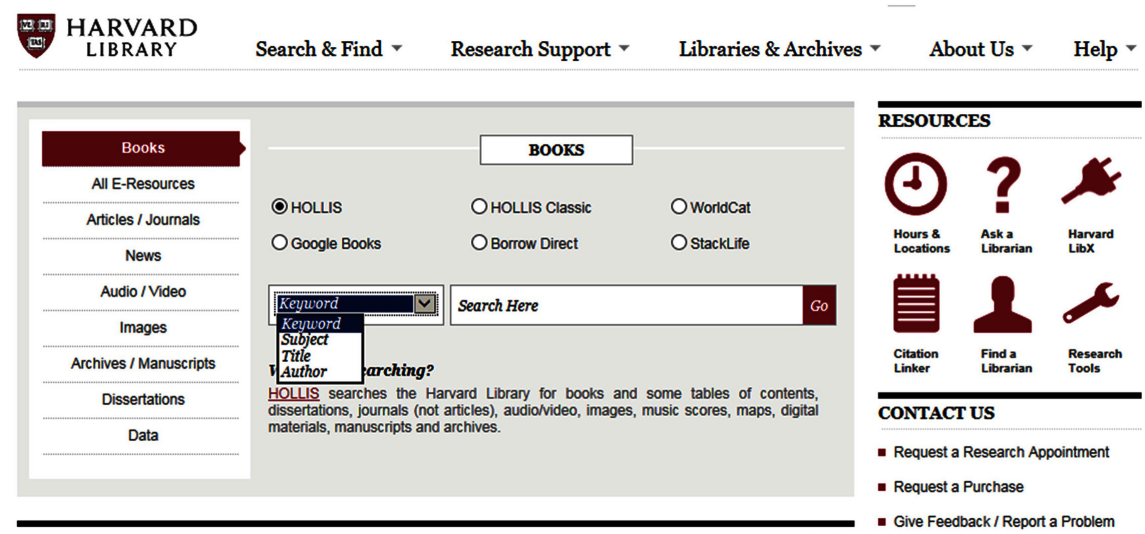

Figure 4. Search Interface of HOLLIS.

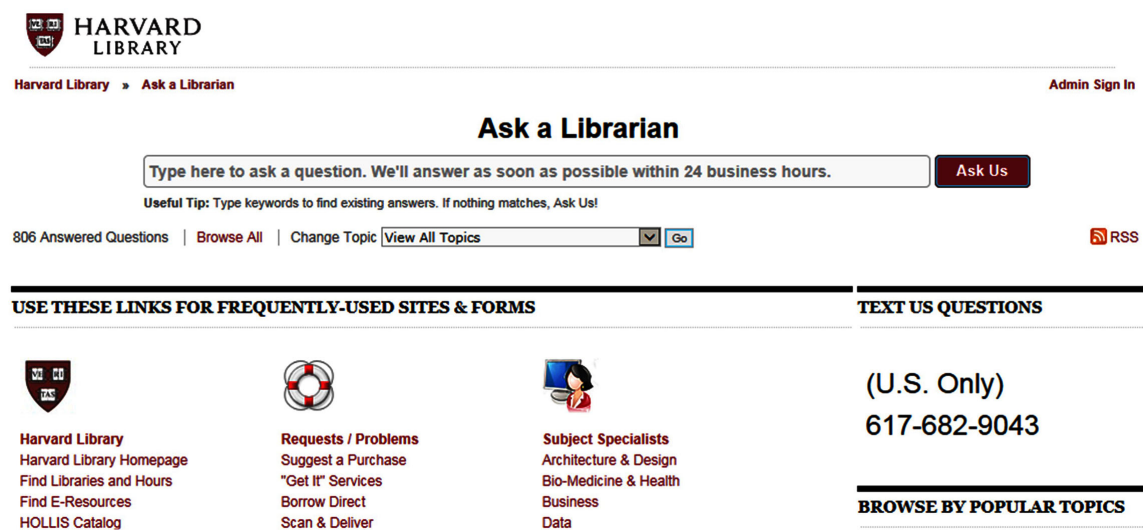

Figure 5. Online consultation platform of Harvard Library. 
Harvard Library established the Document Preservation Office in 1989 (renamed Weissman Preservation Center in March 2000). The center manages and implements Harvard-wide document preservation programs and projects, ensures the availability of collections by assessing the status and needs of document protection, and restores rare books, maps, photographs, etc [8]. The main work of the center includes consultation and on-site service, repair and transcription format conversion.

\section{International Exchanges}

In addition to the close cooperation and exchanges with the libraries of universities in the United States (especially among the eight Ivy League members), Harvard Library have also exchanged frequently with other libraries all over the world. For example, in 2004, Harvard Hilles Library donated 150,000 books to the Sun Yat-sen University Library in China. In 2006, the first Sino-American University Library Director Forum was co-sponsored by Peking University Library and Harvard Library. In 2013, Harvard Library and Wuhan University Library jointly sponsored the Sino-US Collaborative Forum on the Construction of Chinese Literature Resources in Universities. In addition to academic exchanges, there are exchange programs with other libraries in personnel training. Harvard-Yenching Library has frequent exchanges and cooperation with Peking University, Nanjing University, Sun Yat-sen University and Wuhan University in China. A large number of librarians and visiting scholars study and work there for a short time. In addition, Yenching Library provides travel fee or scholarships for more than a dozen researchers conducting East Asia research every year, providing $\$ 400$ for each person's travel and 100 free copies. Researchers from any country can apply for the support. In the academic year 2013-2014, 18 studies were supported, including 7 Chinese, 7 Japanese and 4 Korean studies.

\section{Management System}

Harvard branch libraries have different but strict management systems. The largest Weidner Library belongs to the scientific research library, and generally does not receive visitors. Admission to the library requires an ID card issued by Harvard Library (but children can enter with parents having ID). Like other libraries, books borrowed must be returned within the stipulated date. Although there is no limit on the number of books borrowed, once the book in hand is reserved by other readers, it must be returned within 10 days. If it is overdue, it will be fined and the right to borrow may be cancelled. Even if no penalty notice is received, the penalty will be imposed if the borrowing is overdue. Because each person's information is on the ID, if the fine is not paid in time, it will appear on the final bill. If the users are professors or employees, the library will send a ticket to them through the finance department. Failure to pay a fine will affect the right to borrow and use. The fine is usually $\$ 0.5$ or $\$ 2$ per day, the book reserved is $\$ 0.02$ per minute, and the laptop overdue is $\$ 14.4$ per day. If it 
is lost or not returned, the amount of the fine is the total amount of the price plus the fine, or the minimum of $\$ 100$.

At the exit, all users' schoolbags, backpacks, briefcases, handbags and books will be checked. If an expired ID or someone else's ID is used, the ID will be confiscated. Children under the age of 16 can read in the library with adults but cannot borrow books. Adults must accompany and be responsible for their children's behavior. All users should respect each other and avoid destructive behavior and loud noise. If visitors or guests enter the library, they must contact the director's office in advance.

Persons without a Harvard ID, including Harvard alumni, researchers or $\mathrm{PhD}$ candidates from other research institutes, who are over 18 years old, can apply for certain borrowing rights, but some borrowing cards require fees ( $\$ 75$ for three months, $\$ 125$ for half a year, $\$ 200$ for a year, and $\$ 50$ for alumni over 65 years old) and there is no interlibrary service, and access to electronic resources. Harvard alumni also have some free rights, such as a three-month guest researcher card. The spouse of a Harvard ID holder can apply for a special one-year card (requiring identification) for only $\$ 5$.

\section{The Enlightenments for Other Academic Libraries}

Harvard's branch libraries are different in resources and characteristics, but they all have similar service objectives, that is, to provide high-quality services for teaching, learning, and research. As an excellent example of university library, Harvard Library can provide enlightenments for other academic libraries in the following aspects:

1) Services for teaching, learning and scientific research should be improved in all-round way. It is necessary to mobilize all departments of the whole university, and to optimize literature resources, subject resources, and information resources, to strengthen the role of library.

2) Academic library should construct an advanced information service platform. It should integrate all the resources, introduce new techniques, develop flexible and reliable information retrieval systems and advanced online research tools, and improve service efficiency, so that readers can use library resources conveniently and efficiently.

3) It is necessary to strengthen the construction of subject service team and provide professional services. We should optimize the composition of librarians, recruit, select and train librarians with relevant subject backgrounds and professional qualities in the aspects of department liaison, reference, research consultants, teaching and training, information guide and other services, so as to carry out in-depth service and improve service effect.

4) Academic library should provide personalized refined services. According to the requirements of professional readers of different colleges and departments, it can provide individualized, one-to-one refined services for readers' borrowing, consultation, information integration and screening. 
5) The construction of characteristic resources should be created. It is of great significance to create literature and information resources with professional or regional characteristics, in view of the discipline, specialty or regional characteristics of each university.

6) Services should be improved for special groups of users, such as alumni, disabled persons, children, and the elderly readers. Libraries should reduce service barriers and ensure information fairness and equality.

7) It is of importance to enhance cooperation and exchanges with academic libraries at home and abroad, and to enrich service resources and improve service level.

8) The most important measure is to increase investment, raise funds in many ways, and to encourage alumni, enterprises and other people from all walks of life to contribute actively to supplement the library construction and operation funds.

\section{Conclusion}

In the present article, we firstly introduced the resources of Harvard Library, and then emphasized its services for readers. In conclusion, Harvard Library not only serves teaching, learning and scientific research, but also provides distinctive and refined services, humanized services for disadvantaged groups, public services for the society, as well as many international exchanges. The services of Harvard Library can provide constructive references for other academic libraries especially those in China.

\section{Acknowledgements}

This work was supported by Humanities and Social Sciences Research Project of Qingdao University of Science and Technology (18XB25), Shandong Social Sciences Planning Research Project (18CRCJ05), Shandong Soft Science Research Project (2018RKB01342), and Shandong Social Science Popularization and Application Project (2019-SKZZ-49).

\section{Conflicts of Interest}

The authors declare no conflicts of interest regarding the publication of this paper.

\section{References}

[1] Zhu, Q., Zhang, H., Liu, S., Zhang, C., Zhou, C. and Huang, T. (2012) Report on the Visit to Three Top University Libraries in the US. Journal of Academic Libraries, 30, 6-11.

[2] Li, J., Pan, W., Zhang, D. and Li, G. (2013) Inspiration of Resources Processing and Service of Foreign Top-level University Library to Resource Construction and Service of NLS-Taking Harvard University Library as an Example. Standard Science, 5, 12-17.

[3] Shen, R. (2013) Reform of Harvard Library and Its Enlightenment. Library Devel- 
opment, 6, 63-65.

[4] Yu, D. (2013) Human Resource Management of Harvard Library and Its Enlightenment. Library Theory and Practice, 8, 92-95.

[5] Chen, Q. and Zhang, D. (2013) Subject Service of Harvard Library and Its Enlightenment to China. Knowledge Management Forum, 7, 6-10.

[6] Zhang, Y. (2004) Information Resources Construction of Harvard Library under Internet Environment. Library Work and Study, 5, 62-64.

[7] Wang, X. (2006) Information Resources Construction of Harvard-Yenching Library and Its Enlightenment. Journal of Library Science, 2, 55-56.

[8] Lin, M. (2010) Analysis of Preservation and Conservation System at Harvard Library. Journal of Academic Libraries, 4, 21-26. 